\title{
ANÁLISE AMBIENTAL E DESERTIFICAÇÃO NO PÓLO DE JEREMOABO: EXPLICAÇÃO A PARTIR DA ANÁLISE DOS INDICADORES SOCIAIS DE DESENVOLVIMENTO.
}

\author{
Ákila Britto $^{1}$; Nacelice Freitas ${ }^{2}$ e Higor Alves ${ }^{3}$ \\ 1Bolsista PROBIC/UEFS, Graduando em Geografia pela UEFS,akilasbritto@ hotmail.com, \\ ${ }^{2}$ Prof $^{a}{ }^{a} r^{a}$, Orientadora. Área de Geografia/GEONAT-UEFS, nacegeografic@hotmail.com \\ 3Participante, Graduando em Geografia pela UEFS, higoraes@gmail.com
}

PALAVRAS-CHAVE: desertificação; semiárido; indicadores sociais; desenvolvimento. INTRODUÇÃO

A pesquisa tem por objetivo contribuir com a discussão sobre análise ambiental, partindo dos indicadores de desenvolvimento em destaque o Pólo de Jeremoabo-Ba, indicado através das coordenadas geográficas de $-8^{\circ} 48^{\prime} \mathrm{S}$ e $-10^{\circ} 50^{\prime} \mathrm{S}$ e longitudes: $-37^{\circ} 47^{\prime} \mathrm{W}$ e $-40^{\circ}$ 50 ' W, espaço situado em área susceptível à desertificação no domínio de clima semiárido. Este compreende os municípios de Antas, Canudos, Chorrochó, Coronel João Sá, Glória, Jeremoabo, Macururé, Novo Triunfo, Paulo Afonso, Pedro Alexandre, Rodelas, Santa Brígida, e Uauá, e é uma delimitação para realização da pesquisa intitulada Análise Ambiental no Semiárido Baiano como Subsídio ao Ordenamento Territorial: A Vulnerabilidade à Desertificação no Pólo de Jeremoabo.

O Semiárido brasileiro é caracterizado pelo déficit hídrico, entretanto, não significa falta de água, ao contrário é considerada a região semiárida mais chuvosa do planeta, pois, sua média pluviométrica varia entre $268 \mathrm{~mm}$ a $800 \mathrm{~mm}$ anuais em média (AB'SABER, 2003).

Segundo (HARE, 1977), a medida do tempo necessário para que a terra se restaure dos impactos causados pela seca é a sua capacidade de recuperação, se não for cuidadosamente tratada, a terra nunca mais poderá proporcionar seus recursos como fazia, e as condições próximas ao deserto persistirão, causando uma permanência da baixa produtividade: este declínio duradouro da produtividade é chamado de desertificação.

A análise dos indicadores sociais de um país, região, município, bairro etc, ao longo dos anos, é fundamentalmente importante para a relação e compreensão do desenvolvimento social, político e econômico da sociedade, além da qualidade de vida da mesma. Na atualidade foram incorporadas novas dimensões investigativas em diversos países, passando a produzir relatórios sociais de forma mais sistemática, acreditando que sistemas mais abrangentes de indicadores sociais possibilitariam organizar melhor as ações dos governos, proporcionando o aumento de bem-estar social (BAUER, 1967, apude SOLIGO, 2012, pg 15).

\section{PROCEDIMENTOS METODOLÓGICOS}


Para tal, foi coletado primeiramente informações e dados no site do Instituto Brasileiro de Geografia e Estatistica (IBGE), onde não foram encontrados registros claros e precisos sobre os Índices pesquisados. Fez-se também uma coleta em sites de orgãos similares, como o Programa das Nações Unidas para o Desenvolvimento (PNUD), O Índice de Desenvolvimento Educacional e o Índice de Desenvolvimento Social foram mais dificeis de se obter informações, porém encontrou-se disponíveis na Superintendência de Estudos Econômicos e Sociais da Bahia (SEI) e no Ministério da Educação e Cultura (MEC), sendo assim, o IDEB, foi exposto o intervalo de tempo por eles disponibilizados (IDHM e IDS - 1991, 2000 e 2010 / IDEB 2005, 2007, 2009, 2011 e 2013).

\section{DISCUSSÃO}

O Índice de Desenvolvimento Humano Municipal (IDHM) é uma medida composta de indicadores de três dimensões do desenvolvimento humano: longevidade, educação e renda, que variam de 0 a 1 e quanto mais próximo de 1 , maior o desenvolvimento humano.

GRÁFICO 1 - IDHM DO PÓLO DE JEREMOABO-BA E SEUS ELEMENTOS COMPONENTES.

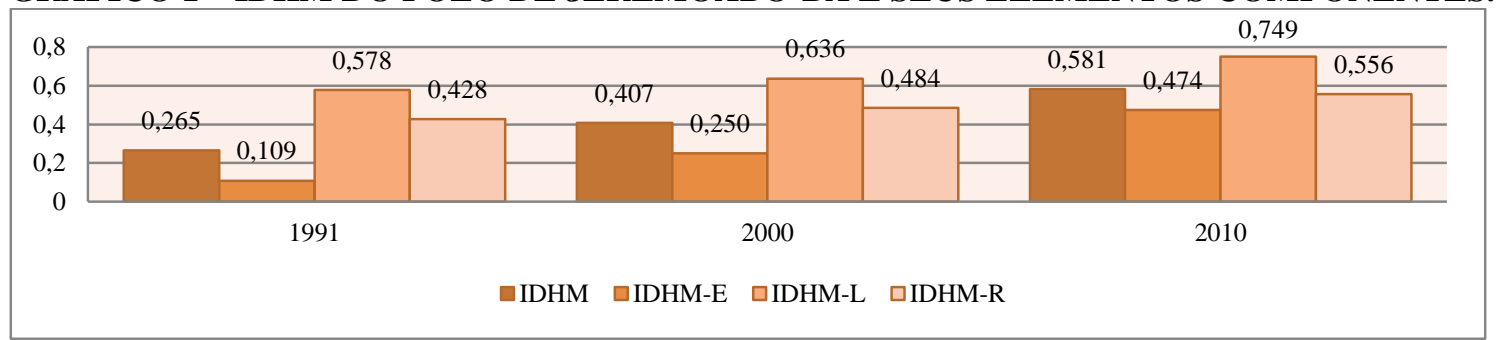

Fonte: PNUD, Ipea e FJP.

Comparando o IDHM com os elementos que o compõem, percebe-se que o Pólo de Jeremoabo possui um índice de longevidade elevado (acima de 0,700), uma renda estável quase linear de um baixo crescimento décadal demostrando uma deficiência nas formas de produção de renda do Pólo de Jeremoabo o índice educacional é baixo (menos que 0,599), sendo dois dos três elementos componentes classificados como baixos na escala do IDHM e apenas um como elevado isso faz com que o IDHM do Pólo seja classificado como baixo com um valor final de 0,581 .

O Índice de Desenvolvimento do Ensino Básico (IDEB) é calculado a partir de dois componentes: a taxa de rendimento escolar (aprovação) e as médias de desempenho nos exames aplicados pelo Inep. Os índices de aprovação são obtidos a partir do Censo Escolar, realizado anualmente pelo MEC.

Efetuados de 2 em 2 anos entre 2005 até 2013 com estudantes do $5^{\circ}$ e $9^{\circ}$ ano (antigas $4^{\text {a }}$ e $8^{\mathrm{a}}$ série), foi elaborado um gráfico do Pólo de Jeremoabo, apontando o crescimento gradual nos resultados do ensino fundamental I com um declínio no ano de 2013. Em contrapartida o ensino fundamental II demonstra um crescimento acentuado de 2005 para 2007, quando obtém 
uma leve queda, alcançando a estabilidade, e retorna ao crescimento gradual até atingir quase o mesmo valor que o ensino fundamental I no ano de 2013. (GRÁFICO 3)

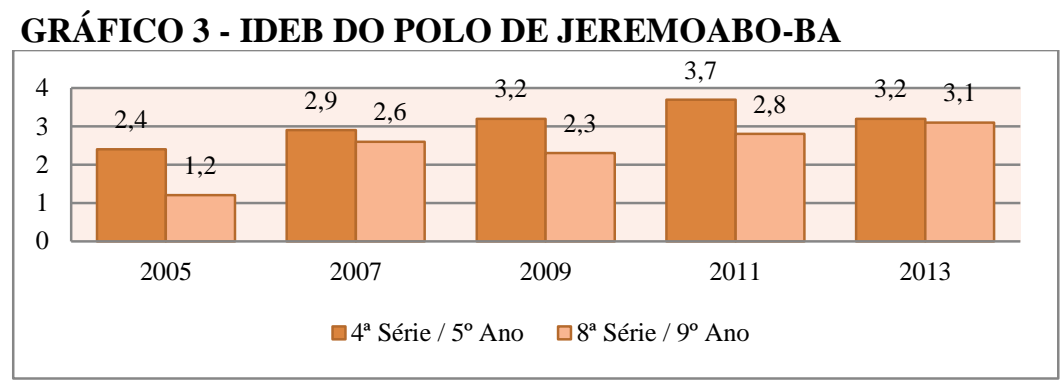

Fonte: ideb.gov.br.

O Índice de Desenvolvimento Social (IDS) dispõe de informações que servem de subsídios para analisar os níveis de desenvolvimento social de um país, estado, município, etc. identificou-se os dados dos municípios que integram o Pólo de Jeremoabo nos anos de 1998, 2000, 2002, 2004 e 2006.

O IDS analisado detem-se na avaliação da qualidade de vida da população em áreas suceptíveis a desertificação (ASD), condições materiasis, remunearação, saúde, educação, habitação, alimentação, transportes, elementos que estão relacionados com a realidade social.

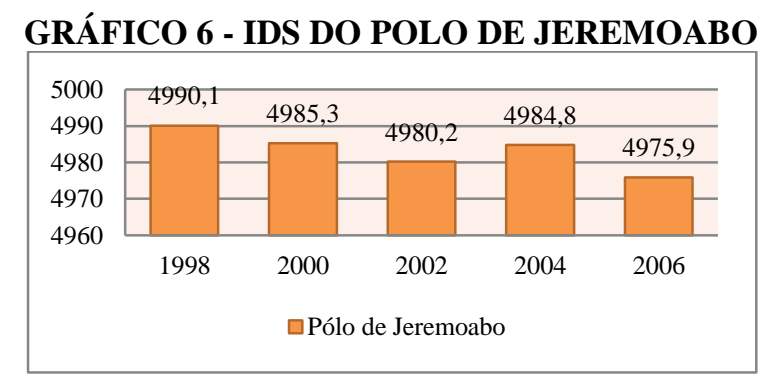

Fonte: SEI.

Os resultados demonstram uma diminuição dos valores nos municípios do Pólo de Jeremoabo, com um destaque ao ano de 2004 que, na tentativa de se reerguer e começar a melhorar os resultados em relação à queda gradual que vinha sofrendo nos anos de 1998 a 2002, observa-se que não ocorre de forma tão promissora já que os índices voltam a declinar no ano de 2006 para um valor mais baixo que os números apresentados em 2002.

\section{CONSIDERAÇÕES FINAIS}

A leitura dos dados do IDHM permitiu afirmar que um crescimento gradual ao longo das décadas estudadas, com alguns municípios chegando a dobrar o valor, mas mesmo em ascensão.

Os dados referentes ao IDHM-E nos anos pesquisados aumenta pelo fato de se obter mais crianças nas escolas e uma diminuição dos abandonos escolares, e pelo Programa de Alfabetização de Jovens e Adultos (AJA), além disso, a frágil, porém importante melhora nas condições de vida dessas famílias que agora conseguem o mínimo para sua sobrevivência 
reflete no aumento do IDHM-L com o investimento feito nas áreas de saúde, assim como, o conhecimento da população quanto aos cuidados para se evitar doenças, a melhoria do saneamento básico e outros fatores, decorrentes de projetos de políticas públicas aplicados pelo Governo Federal. O IDHM-R mostra que a renda municipal não vem crescendo mesmo com essas mudanças indicando um déficit da produção, ou elevação do índice de desemprego que está sendo gerado nessas condições de urbanização.

A queda dos valores do IDS em 2006 ocorre por falta de continuidade da Política Nacional de Assistência Social (PNAS/2004), na perspectiva da criação do Sistema Único de Assistência Social (SUAS). Esta iniciativa, decididamente, traduz o cumprimento das deliberações da IV Conferência Nacional de Assistência Social, realizada em Brasília, em dezembro de 2003, e denota o compromisso do Ministério do Desenvolvimento Social e Combate à Fome (MDS/SNAS), e do Conselho Nacional de Assistência Social em materializar as diretrizes da Lei Orgânica da Assistência Social (LOAS).

\section{REFERÊNCIAS}

AB'SABER, Aziz Nacib. Os domínios de natureza no Brasil: potencialidades paisagísticas. São Paulo: Ateliê Editorial, 2003

BRASIL, Ministério do Meio Ambiente. Programa Nacional de Combate à Desertificação e Mitigação dos Efeitos da Seca PAN-Brasil. Brasília, DF: Ministério do Meio Ambiente; Secretaria de Recursos Hídricos, 2005.

CASTELLETTI, C. H. M.; SANTOS, A. M. M.; SILVA, J.M. C. da. Quanto ainda resta de caatinga uma estimativa preliminar. In: LEAL, I. R. et al. Ecologia e conservação da caatinga. Recife: UFP, 2003.

CAVALCANTI, E.R.; COUTINHOS, F.R.; SELVA, V.S.F. - Desertificação e Desastres Naturais na Região do Semiárido Brasileiro. Revista Cadernos de Estudos Sociais. v. 22, n. 1. jan./jun., 2006. Recife: Editora Massangana, 2007.

DANTAS, C. C. G. Gestão ambiental: um estudo sobre a percepção do problema da desertificação no Estado do Rio Grande do Norte. 2005. Dissertação (Mestrado em Ciências em Engenharia de Produção) Centro de Tecnologia. Universidade Federal do Rio Grande do Norte, Natal, 2005.

HARE, F. K.; WARREN, A.; MAIZELS, J.K.; KATES, R.W.; JOHNSON, D.L.; HARING, K.J.; GORDUÑO, M.A. Desertification: its causes and consequences, United Nations, Pergamon Press.1977. Desertificação: causas e consequências. Fundação Calouste Gulbenkian, Lisboa. 1992.

LIMA, Ricardo da Cunha Correa; CAVAlCANTE, Arnóbio de Mendonça Barreto; MARIN, Aldrin Martin Perez. Desertificação e Mudanças Climáticas no Semiárido Brasileiro. Campina Grande: INSA-PB, 2011. 209 p.

LUNA, R. M. Desenvolvimento do Índice de Pobreza Hídrica (IPH) para o Semi-Árido Brasileiro. Tese de Doutorado. Programa de Pós-Graduação em Engenharia Civil, área de concentração em Recursos Hídricos. Departamento de Engenharia Hidráulica e Ambiental (DEHA). Universidade Federal do Ceará (UFC). Fortaleza, 2007. 138f.

MMA, Secretaria de Recursos Hídricos, Universidade Federal da Paraíba; SANTANA, M.C., Organizador. Atlas das Áreas Susceptíveis à Desertificação do Brasil, Brasília: MMA, 2007.

MONTEIRO, C.A. A dimensão da pobreza, da fome e da desnutrição no Brasil, Estudos Avançados. vol.17 no.48 São Paulo May/Aug. 2003

MOURÃO, P.R. Contributo para o estudo econômico dos indicadores regionais. Revista Estudos regionais $n^{\circ} 12$, Departamento de Economia/Núcleo de Investigação em Políticas Económicas, Universidade do Minho, Portugal. 2006

PAREJO, L. C. Desertificação: Causas e consequências do mau uso do solo. 2006. São Paulo. (Revista UOL) http://educacao.uol.com.br/disciplinas/geografia/desertificacao-causas-e-consequencias-do-mau-uso-do-solo.htm acessado em 08/04/2015 ás $16 \mathrm{~h} 37 \mathrm{~min}$.

RODRIGUES, Maria Cecilia Prates. O índice de desenvolvimento social (IDS). Revista Conjuntura Econômica, v. 47, n. 2, p. 45-51, 1993.

ROXO, M. J.; MOURÃO, J. M.; CASIMIRO, P. C. Políticas agrícolas, mudanças de uso do solo e degradação dos recursos naturais-Baixo Alentejo Interior. Mediterraneo, v. 12, n. 13, p. 167-189, 1998.

SÁ, Iêdo Bezerra; SILVA, Pedro Carlos Gama. SEMIÁRIDO Brasileiro: pesquisa, desenvolvimento e inovação. Pernambuco: Embrapa Semi-Árido, 2010, 402 p.

SOLIGO, V. Indicadores: conceito e complexidade do mensurar em estudos de fenômenos Sociais. Est. Aval. Educ., São Paulo, v. 23, n. 52, p. 12-25, mai./ago. 2012 